\title{
Broadening the Participation of Rural Students in Engineering: Exploring Community Perspectives
}

\section{Stacey L. Vaziri, Virginia Tech Department of Engineering Education}

Stacey Vaziri is a PhD candidate in the Department of Engineering Education at Virginia Tech. She received her M.S. in Materials Engineering from Purdue University and her B.S. in Chemical Engineering from North Carolina State University. Her research interests include access to higher education and broadening participation in engineering.

\section{Dr. Marie C Paretti, Virginia Polytechnic Institute and State University}

Marie C. Paretti is a Professor of Engineering Education at Virginia Tech, where she directs the Virginia Tech Engineering Communications Center (VTECC). Her research focuses on communication in engineering design, interdisciplinary communication and collaboration, design education, and gender in engineering. She was awarded a CAREER grant from the National Science Foundation to study expert teaching in capstone design courses, and is co-PI on numerous NSF grants exploring communication, design, and identity in engineering. Drawing on theories of situated learning and identity development, her work includes studies on the teaching and learning of communication, effective teaching practices in design education, the effects of differing design pedagogies on retention and motivation, the dynamics of cross-disciplinary collaboration in both academic and industry design environments, and gender and identity in engineering.

\section{Dr. Jacob R Grohs, Virginia Polytechnic Institute and State University}

Jacob Grohs is an Assistant Professor in Engineering Education at Virginia Tech with Affiliate Faculty status in Biomedical Engineering and Mechanics and the Learning Sciences and Technologies at Virginia Tech. He holds degrees in Engineering Mechanics (BS, MS) and in Educational Psychology (MAEd, $\mathrm{PhD})$.

\section{Dr. Liesl M Baum, Virginia Polytechnic Institute and State University}

Dr. Liesl Baum is the Associate Director for Professional Development at the Center for Excellence in Teaching and Learning. She is a former middle school teacher and spent seven years teaching in Virginia public schools. Her research interests and goals are to develop a frame of mind that allows for creativity to develop among students and faculty of all levels. She works with university faculty to identify and build teaching strategies that encourage creativity for learning. Her research and work interests remain across the full realm of education and preparing educators to design and develop teaching and learning opportunities that encourage students to take risks, inquire across multiple disciplines, and participate in grand challenges. Liesl received her B.S. in Middle Education and M.S. in Educational Technology, both from Radford University. She received her doctorate in instructional design and technology from Virginia Tech.

\section{Dr. Marlena McGlothlin Lester, Virginia Tech}

Marlena McGlothlin Lester is the Director of Advising for the Department of Engineering Education at Virginia Tech. She leads the undergraduate advising team and oversees the advising process for all General Engineering students. She is responsible for the development of a hands-on, minds-on orientation model for all first-year engineering students, the creation of a comprehensive engineering major exploration tool, Explore Engineering, and enhancement of the academic planning resources available for first-year engineering students. Marlena strives to transform the advising experience for students and advisors through communication, collaboration, and consistency.

\section{Dr. Phyllis Leary Newbill}


Dr. Phyllis Newbill is the Outreach and Engagement Coordinator at the Institute for Creativity, Arts, and Technology (ICAT) at Virginia Tech. She serves as the liaison between the university and the Science Museum of Western Virginia and directs the Virginia Tech Science Festival. She has worked in science education at preschool, high school, university, and adult education levels. She has both formal and informal instructional experience. Her research interests include museum learning, science education, critical and creative thinking, outdoor education, gender issues in education, rural education, and incorporating the arts into standards-based instruction. She received a double B.S. in Geology and English from Radford University in 1998. She received her M.S. In Environmental and Engineering Geosciences from Radford University in 2001. She earned her Ph.D. from Virginia Tech in Instructional Design and Technology in 2005. Phyllis has worked with ICAT and its prototypes since 2007. 


\title{
Broadening the Participation of Rural Students in Engineering: Exploring Community Perspectives
}

\begin{abstract}
Interest in increasing both the number and diversity of students enrolling in engineering has resulted in significant research on students' career choice decisions. Notably, however, while general trends have emerged, many of the models that have been developed focus on majority students. But an increasing body of work on students from a variety of specific demographic groups highlight unique socio-cultural experiences that influence individuals' career choice decisions. Most relevant to this study, literature on rural students suggests that the lack of high-level STEM courses in rural schools and a desire to stay close to home played key roles in limiting students' consideration of engineering as a potential career. However, little work has explored how rural communities support and promote engineering as a career choice for their students. Therefore, this study explored the ways in which rural communities provide support to help students make fully informed decisions about engineering as a college major.
\end{abstract}

The findings presented here come from Phase 2 of a three-phase study exploring engineering career choice among rural students. Using interview and focus group data collected from current engineering students in Phase 1, Phase 2 turned to community members, including high school personnel, local industry leaders, members of local governments, and members of key community organizations (e.g., 4-H). Using interviews with 16 participants across 3 communities, we address the following question: What beliefs, experiences, and practices characterize community members or organizations who support or encourage rural students to choose engineering?

The interviews explored the participants' perceptions of their community overall, resources that helped students explore postsecondary options, barriers students faced to enrolling in postsecondary education/engineering, understanding of engineering as a field both generally and for students from that community, and ways Virginia Tech can be a better community partner and fulfill its mission as a public institution. This project aims to broaden participation in engineering by gaining a holistic understanding of the communities that effectively support engineering major choice for rural students and provide contextual methods of increasing support for students from these rural areas.

\section{Introduction and Background}

Current rates of engineering enrollment are not sufficient to meet the needs of the engineering workforce. To meet this need, this project focuses on broadening participation of rural students in engineering by better understanding how rural communities support and promote engineering as a career choice. Despite vast differences in the geography and history of rural areas in the state of Virginia, these regions face a similar set of challenges to future growth and prosperity. For example, although $17.5 \%$ of Virginia's population reside in rural areas, these communities only support $11.5 \%$ of the state's jobs. In addition, the poverty rate was $120.5 \%$ of the overall U.S. rate for 2010-2014 and only $27 \%$ of the population holds an associate degree or higher, 
compared to $51 \%$ for the state and $46 \%$ for the nation $[1,2]$. Moreover, distance to and from schools in the state's rural regions can be quite significant. Most counties have only one high school, and students live 30 minutes or more from their school, with school bus travel times even longer. Coupled with lack of public transportation, this distance can present barriers to after-school or other supplemental programs designed to spark student interest and engagement. Given such conditions, students from the rural communities in Virginia face a number of region-specific challenges related to educational access and attainment $[3,4]$.

An increasing body of work has sought to better understand the needs and challenges of rural students. Recent studies on career choice in Appalachia have identified the importance of rural cultural beliefs about family, community, and work in shaping students' career paths [5-7]. Rural schools are also often smaller and lack the resources necessary to provide the rigorous math and science curriculum needed to help prepare students to be competitive applicants and enter college engineering programs. Such resource challenges are compounded by geographic ones, particularly in Appalachia; rural schools in southwestern Virginia, for example, typically serve widely dispersed populations, with students easily living 30-60 minutes or more from the school on roads that wind through mountainous landscapes, making access to after-school and weekend activities more difficult for students, parents, and community members.

Given such factors, work by Carrico, Matusovich, Boynton, and Paretti explored engineering career choice among rural high schools in the Appalachian regions of Virginia and Tennessee [8-13]. This work found that students' pathways to a career choice were heavily influenced by the people and values of the local community; family, teachers, and friends, in particular, often played a key role in exposing students to engineering majors and careers related to their general interest in engineering or related fields (e.g., math, physics) [10, 13]. Of particular concern here are the experiences of girls in these communities. Studies on rural populations where exposure to multiple careers is limited indicate that participants often have very limited conceptions regarding their potential futures (including possible future careers) [9, 14, 15]. Research on gender and career choice in particular found that rural adolescent girls envisioned their futures largely in terms of personal attributes (e.g., home, family) but could say little about future goals or expectations around higher education or potential careers [14].

The economics of the study region highlight the high stakes these rural communities face as they prepare students to make career choices because those choices impact the sustainability of the community itself. Discussions with regional companies highlight gaps in their ability to hire and retain qualified engineering professionals, while business incubators such as Virginina Tech's Corporate Research Center are increasing regional opportunities for innovation and entrepreneurship. Such conditions echo published state and regional reports and commentaries (e.g., [16-18]) and point to the need to help diversify students' opportunities, while the absence of students from these communities in our classrooms points to the need to broaden participation from these underserved areas.

This project focuses on influential individuals (e.g. teachers, guidance counselors, local engineers, community leaders) within rural communities to identify community resources that serve as key supports (e.g., available employment, civic programs) to engineering as a career 
choice for rural students, as well as barriers that hinder support and strategies for addressing those barriers. Specifically, the aim of this study was to address the following research questions:

RQ1. How do community members describe the resources that serve as key supports as well as the barriers that hinder support in their community?

RQ2. What strategies do community members perceive their community should implement to enhance their ability to support engineering as a potential career choice?

\section{Theoretical Framework}

To frame our study, we draw on Perna's conceptual model of student college choice [21], illustrated in Figure 1. Perna's model incorporates the rational model of human capital investment, which assumes that an individual chooses to invest in higher education based on their comparison of the expected benefits and costs. Human capital theory also suggests that the cost benefit analysis is influenced by the students' academic preparation for college and availability of resources to cover the costs. This approach offers a framework for understanding decision making but has limited usefulness for understanding sources of differences in college choice across groups, primarily because it does not consider the nature of information that is available to individuals. To address this shortcoming, Perna's model draws on sociological approaches and nests human capital investment model within four layers of context: (1) the individual's habitus, (2) the school and community context, (3) higher education context, and (4) the social, economic, and policy context.

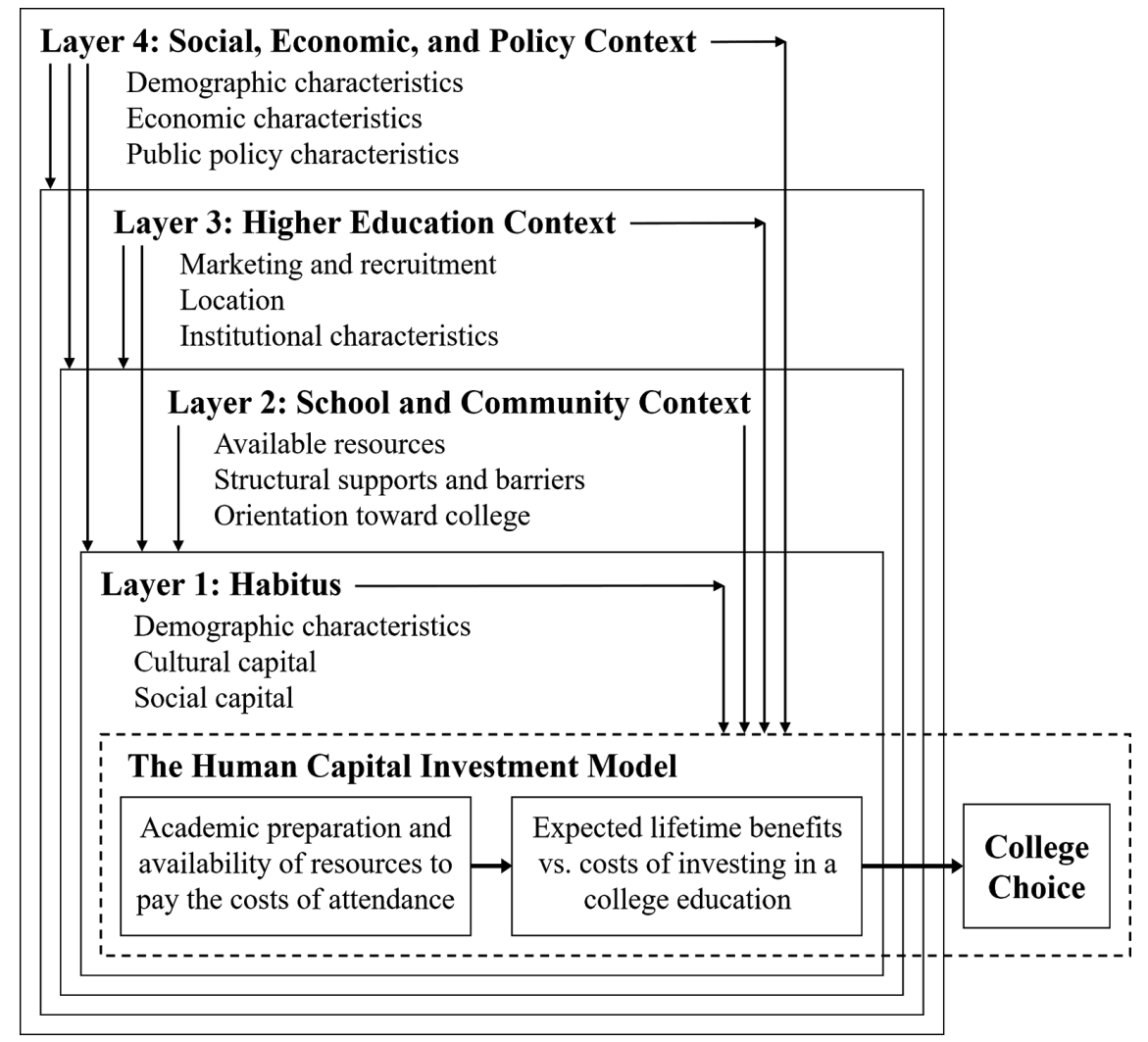

Figure 1. Perna's Conceptual Model of Student College Choice [21] 
Habitus, the innermost layer of Perna's model, refers to the internal system values and beliefs acquired from one's immediate environment that guides future behaviors and choices [22]. Through everyday experiences, perceptions of what is right and appropriate are internalized, ultimately defining what is achievable for an individual and bounding their college-related expectations and aspirations. The habitus layer incorporates students' demographic characteristics, cultural capital, and social capital. The next layer, the school and community context, follows McDonough's [23] concept of "organizational habitus" and recognizes the school and/or community's impact on students' belief system and behavior, including college-going.

The third layer of context considers the ways in which higher education institutions influence student college choice. Influential factors associated with higher education institutions include the passive transmission of information based on their proximity to students, active transmission of information as a result of their marketing and recruitment efforts, institutional characteristics, and their ability to select which applicants may enroll. Prospective students use this information to determine the personal fit and their chances of admission and self-select institutions they believe meet their needs [24]. Lastly, the outermost layer recognizes the ways in which the social, economic, and policy context shapes student college choice through changes in social forces, economic conditions, and public policies. Potential factors include demographic characteristics of the population, characteristics of the local labor market, K-12 educational policies, and policies that improve college access [25].

\section{Methods}

The study presented here is the second phase of a three-phase project exploring engineering career choice among rural students. Phase 1 focused on undergraduate engineering students at Virginia Tech who graduated from targeted rural high schools and aimed to identify key influences on their decision to attend college and major in engineering. Based on findings from Phase 1, we selected three rural communities to explore further. Because most counties in the study region contain only one or two high schools, we considered each county as a separate community and chose the counties where we interviewed multiple students who provided concrete supports and barriers within their communities. We conducted a single-case study with the three communities as embedded units of analysis [26]. Within each embedded unit, we identified and interviewed key individuals from the students' high schools and the surrounding community (e.g. teachers, guidance counselors, community leaders, local engineers) to better understand how rural communities support college enrollment and engineering as a major choice, as well as identify barriers that hinder support and strategies that would enhance their ability to support engineering as a potential career choice. 


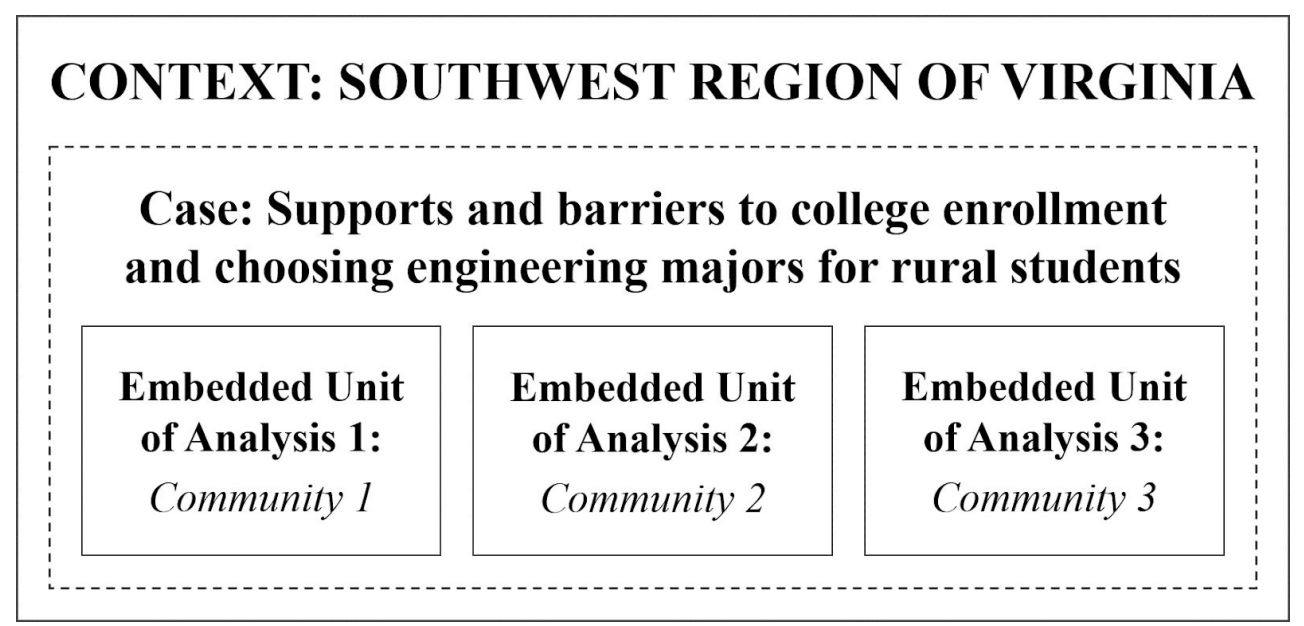

Figure 2: Single-case embedded design

\section{Participants and Data Collection}

Based on the findings from Phase 1, we developed an interview protocol and used snowball sampling to reach out to community members and organizations that emerged as salient in students' experiences. In addition, in each community the high school principal, guidance counselors, teachers, personnel from other local education institutions (e.g., Governor's schools, career and technical schools, community colleges), the director of education, relevant members of town government (e.g., chamber of commerce head, cooperative extension agent), and local engineers were recruited to participate in interviews.

We conducted semi-structured individual interviews with fourteen community members, five from community 1 , four from community 2 , and five from community 3 . The participants were associated with public high schools, Governor's schools, community colleges, technical education centers, Virginia Cooperative Extension, and the chamber of commerce. The interviews lasted approximately 40-60 minutes and aimed to understand (1) opportunities or experiences in their community that help students explore options after high school and engineering specifically, (2) barriers that might prevent students in their community from going to college and/or choosing engineering majors, and (3) how Virginia Tech can be a better partner and a better land-grant institution. For example, participants were asked "Thinking specifically about students' plans after high school, what kinds of opportunities or experiences are you aware of that would help students explore options for after high school?" Follow-up questions here explored the opportunities and resources that would help students consider engineering as a career specifically. In addition, interviews with individuals that students identified as influential in Phase 1 were tailored based on students' experiences with that person or program to help us understand the beliefs, perceptions, and experiences that framed the participants' support of the student. The interview question "Students from this area have talked about X [based on interview data - e.g. high school teachers, $4 \mathrm{H}$, community college] as a key support for their choice of engineering. Why do you think X has been so supportive?" yielded this information.

Data Analysis 
The interview transcripts were analyzed following the practices outlined in Miles, Huberman, and Saldaña [27], beginning with a priori coding guided by the Perna's model and our research questions, but allowing other descriptive codes to emerge from the data. Samples of provisional codes include "supports for engineering majors" and "barriers to accessing higher education." The data was analyzed first within the case and then across embedded units [27], with each community as an embedded unit of analysis, as noted above. All 14 interview transcripts were coded using the qualitative data analysis software Dedoose. Coding sought to identify community resources that serve as key supports (e.g., available employment, civic programs) as well as barriers that hinder support and strategies for addressing those barriers.

\section{Results}

The participants discussed several supports available in their communities that help students explore options for after high school and assist with college-related processes, including dual enrollment courses, career fairs, assistance with FASFA forms, STEM activities (robotics club, STEM camps, etc.), and career coaches. Several participants also discussed the impact of The Reality Store, an interactive education experience in household money management typically run by the school or Virginia Cooperative Extension. Students select an occupation they think they would like to have as an adult and are given a salary based on that occupation that they will need to spend on the necessities and luxuries they envision as part of their lives. They visit booths representing the housing industry, utilities, grocery stores, clothing stores, financial institutions, health insurance/medical care, etc. The goal of this experience is to help students understand whether their selected occupation will provide the financial resources needed to provide the type of lifestyle they want. Lastly, students considering attending a two-year institution prior to enrolling at a four-year university benefit from the community college access programs and guaranteed admissions agreements between community colleges and four-year universities.

Key barriers to higher education and choosing engineering majors faced by rural students from these communities include limited access to advanced coursework, low high school graduation rates, concerns about the cost of higher education, and lack of exposure to career options, particularly in engineering. Consistent with previous research, the desire of rural youth to maintain their connections with their family, community, and rural lifestyle can also act as a barrier and lead them to choose local educational and career options rather than leaving the community. In addition, guidance counselors in rural high schools are overloaded with work and do not have the time or resources to assist students with college-related processes. The Virginia Community College System (VCCS) implemented career coaches in Virginia high schools to alleviate this problem. Career coaches are community college employees who are based in local high schools and assist high school students in defining their career aspirations and identifying the postsecondary programs that align with their educational and financial goals.

One key part of the interview aimed to identify ways that Virginia Tech can support rural communities. Most participants suggested that Virginia Tech increase their presence in rural communities and their interactions with rural students to help lower the barriers and become a better partner and land-grant institution. Some of these participants believed that exposure to 
university information (majors and opportunities available), and engineering fields specially, would better ensure that rural students are able to make informed choices about postsecondary education and engineering as a potential career choice. For example, one community college faculty member suggested that Virginia Tech develop and share well-researched activities that they can use for outreach with local students to teach them about opportunities in engineering. As shown in the following quote, they believed these activities should be designed for students throughout their K-12 education career.

"What I would like to see from Virginia Tech, what I think could really change things is a set of activities that they could, then, hand off to me and say, "You or some of your students, go into these schools and do this activity, and that will teach these students about opportunities in engineering." That's really what could change things, but it can't be just the high school level, and it can't just be middle. You've got to hit them like two, three, four, five times during their school career. So, here's an activity for second graders. Here's one for fourth graders. Here's one for seventh graders or something. It's not just for southwest Virginia. I mean, that's good for the commonwealth. I think that could do some really good things."

Other community members were concerned about rural students transition to Virginia Tech and meeting the needs of nontraditional students. For example, several community members believed that Virginia Tech should partner with local higher education centers or community colleges to create two-year or four-year degree programs associated with Virginia Tech that students could complete locally. This would benefit nontraditional students who need to stay in their local community and motivate community college students to engage in their coursework. Another community college faculty member shared their concern about how nontraditional students would transition to a larger four-year university:

"The students at the community college level, for a lot of them, school is not their life. It's just one piece of the rest of their life, and the rest of their life has a lot going on. And I've thought about it, what happens when they do get to Virginia Tech, where the expectation is a lot more rigid, and if you miss class or if something happens, and I'm sure it's different professor to professor, but it seems a lot less forgiving for those kind of life circumstances, at least for undergraduate students."

At an institution with smaller class sizes, they are able to work with these nontraditional students (i.e., students with a family, working students) to ensure they can progress through their degree program. They suggested that Virginia Tech work with transfer students to ensure they have a smooth transition and are successful in their programs at Virginia Tech. Lastly, a community member who served on the Industrial Development Authority believed that Virginia Tech should increase their presence in the community and use their relationships with partners in industry to encourage more companies to move to the area and increase job opportunities.

\section{Conclusions}


This study explored the perspectives of key individuals in rural communities on the resources that serve as supports for students and the barriers they may face to enrolling in higher education and choosing engineering majors. The supports and barriers were primarily related to academic preparation for college, cultural beliefs, and exposure to potential careers, particularly in STEM fields. Past research has documented the significant influence of academic preparation on student outcomes and that rural students often lack access to rigorous courses [28, 29, 30]. Community members identified Governor's Schools as a key support to address this barrier. The Virginia Governor's School Program was designed to assist school divisions with the need to provide a rigorous curriculum to the population of high-achieving students. The Governor's School provides these students with academic opportunities beyond what is offered in their home schools. However, students must be accepted into the program to gain access to these courses. Our study indicates that this resource may not be addressing the issue for all students. In addition, dual enrollment courses were identified as a significant support for students. Consistent with past research, our findings suggest that increasing student access to dual enrollment courses may help to better prepare rural students for college [31,32].

The influence of rural students' cultural beliefs and the lack of exposure to STEM fields has also been documented in the literature [29, 33, 34]. However, one significant contribution of this study was reaching the community members often overlooked when studying rural students' college and major choice. They were able to provide us with their perceptions of supports and barriers, as well as concrete recommendations for addressing the barriers. Consistent with past research, our data suggest that we should consider students' interest in engineering fields and their exposure to related careers by incorporating engineering activities into their K-12 education and using interventions outside the classroom to teach students about engineering (e.g., community events, camps). However, community members recommend relating these activities to local values and involving Virginia Tech in these interventions. Thus, interventions should expose students to engineering in ways consistent with their family values and desire to remain local (e.g., involving local engineers, focus on agriculture), as well as exposing them to individuals within colleges and universities. In addition, our findings identified key partnerships with both local community colleges and with organizations such as $4 \mathrm{H}$ programs that could provide important local support for students. In the final phase of our study, we plan to share this information through participatory design workshops with key groups of community members who work with rural students.

\section{Acknowledgements}

This material is based upon work supported by the National Science Foundation under Grant Number 1734834. Any opinions, findings, and conclusions or recommendations expressed in this material are those of the author(s) and do not necessarily reflect the views of the National Science Foundation.

\section{References}

[1] State Council of Higher Education for Virginia (SCHEV), "The Virginia plan for higher education: Annual report for 2016 to the General Assembly of Virginia," SCHEV, 
Richmond, VA, USA, 2017. Retrieved from

http://www.schev.edu/docs/default-source/virginiaplan/Reports-andUpdates/annualreport2 016finalad3eb850bece61aeb256ff000079de01.pdf

[2] J. McFarland, B. Hussar, C. de Brey, T. Snyder, X. Wang, S. Wilkinson-Flicker, S. Gebrekristos, J. Zhang, A. Rathbun, A. Barmer, F. Bullock Mann, and S. Hinz, "The condition of education 2017," NCES, IES, U.S. Department of Education, Washington, DC, USA, NCES 2017-144, 2017.

[3] S. Ardoin, College aspirations and access in working-class rural communities: The mixed signals, challenges, and new language first-generation students encounter. Landham, MD, Lexington Books, 2017.

[4] P. M. McDonough, R. E. Gildersleeve, and K. M. Jarsky, "The golden cage of rural college access: How higher education can respond to the rural life," In Schafft \& Jackson (Eds.), Rural education for the twenty-first century: Identity, place, and community in a globalizing world, University Park, PA, Pennsylvania University Press, 2010, ch. 10, pp. 191-209.

[5] S. R. Ali and E. H. McWhirter, "Rural Appalachian youth's vocational/educational postsecondary aspirations applying social cognitive career theory," Journal of Career Development, vol. 33, no. 2, pp. 87-111, 2006, doi: 10.1177/0894845306293347.

[6] S. R. Ali and J. L. Saunders, "College expectations of rural Appalachian youth: An exploration of social cognitive career theory factors," The Career Development Quarterly, vol. 55, no. 1, pp. 38-51, 2006, doi: 10.1002/j.2161-0045.2006.tb00003.x.

[7] S. L. R. Bennett, "Contextual affordances of rural Appalachian individuals," Journal of Career Development, vol. 34, no. 3, pp. 241-262, 2008, doi: 10.1177/0894845307311252.

[8] C. A. Carrico, M. Boynton, H. M. Matusovich, and M. C. Paretti, "Development of an interview protocol to understand engineering as a career choice for Appalachian youth," in American Society for Engineering Education Annual Conference and Exposition, Atlanta, GA, 2013.

[9] C. A. Carrico, M. Boynton, H. M. Matusovich, and M. C. Paretti, "Supporting students' plans for STEM careers: How prepared are high school educators in Appalachia to help?" in American Society for Engineering Education Annual Conference and Exposition, Seattle, WA, 2015.

[10] C. A. Carrico, "Voices in the Mountains: A Qualitative Study Exploring Factors Influencing Appalachian High School Students' Engineering Career Goals," Ph.D., Engineering Education, Virginia Polytechnic Institute and State University, Blacksburg, VA, 2013.

[11] H. M. Matusovich, C. A. Carrico, M. C. Paretti, and M. A. Boynton, "Engineering as a Career Choice in Rural Appalachia: Sparking and Sustaining Interest," International Journal of Engineering Education, vol. 33, no. 1B, pp. 463-475, 2017. 
[12] M. Boynton, C. A. Carrico, H. M. Matusovich, M. C. Paretti, and A. P. R. Taylor, "Exposure matters: Understanding the experiences of rural cultures," in ASEE/IEEE Frontiers in Education Conference, Oklahoma City, OK, 2013.

[13] M. Boynton, "People not print: Exploring engineering future possible self development in rural areas of the Cumberland Plateau," Ph.D. dissertation, Engineering Education, Virginia Polytechnic Institute and State University, Blacksburg, VA., 2014.

[14] C. A. Carrico, H. M. Matusovich, M. C. Paretti, and M. Boynton, "Maybe I am interested in engineering, does that matter?," in American Society for Engineering Education Annual Conference and Exposition, Indianapolis, IN, 2014.

[15] S. R. Ali and J. L. Saunders, "The career aspirations of rural Appalachian high school students." Journal of Career Assessment, vol. 17, no. 2, pp. 172-188, 2009, doi: 10.1177/1069072708328897.

[16] Virginia Tobacco Region Revitalization Commission, "Strategic plan," Virginia Tobacco Region, Richmond, VA, 2016.

[17] J. Morgan, "SWVA economic analysis report," Cumberland Plateau Planning District Commision, Lebanon, VA, 2010.

[18] J. Whitt, "CEO insights: Sowing seeds for future growth," Roanoke-Blacksburg Technology Council, Roanoke, VA, 2016.

[19] U.S. Bureau of Labor Statistics, “Employment by detailed occupation.” (Sept. 4, 2019). Distributed by Employment Projections Program, Washington, DC.

[20] D. Langdon, G. McKittrick, D. Beede, B. Khan, and M. Doms, "STEM: Good jobs now and for the future," U.S. Department of Commerce, Economics and Statistics Administration, Washington, DC, USA, ESA Issue Brief \#03-11, 2011.

[21] L. W. Perna, "Studying college choice: A proposed conceptual model," in Higher Education: Handbook of Theory and Research, vol. 21, J. C. Smart, Ed. New York, NY, Springer, 2006, pp. 99-157.

[22] P. Bourdieu and L. J. D. Wacquant, An invitation to reflexive sociology. Chicago, IL: University of Chicago Press, 1992.

[23] P. M. McDonough, Choosing colleges: How social class and schools structure opportunity. Albany, NY: State University of New York Press, 1997.

[24] C. F. Manski and D. A. Wise, College choice in America. Cambridge, MA: Harvard University Press, 1983.

[25] L. W. Perna, M. W. Klein, and M. K. McLendon, "Insights and implications for state policy-makers," The ANNALS of the American Academy of Political and Social Science, vol. 655, no. 1, pp. 209-230, Sept. 2014, doi: 10.1177/0002716214539895.

[26] R. K. Yin, Case study research: Design and methods, 4th ed. Thousand Oaks, CA, Sage Publications, 2009. 
[27] M. B. Miles, A. M. Huberman, and J. Saldaña, Qualitative data analysis: A methods sourcebook, 3rd ed. Thousand Oaks, CA, Sage Publications, 2013.

[28] D. J. Gagnon and M. J. Mattingly, "Advanced placement and rural schools: Access, success, and exploring alternatives," Journal of Advanced Academics, vol. 27, no. 4, pp. 266-284, 2016, doi: 10.1177/1932202X16656390.

[29] L. Henley and P. Roberts, "Perceived barriers to higher education in STEM among disadvantaged rural students: A case study," Inquiry: The Journal of the Virginia Community Colleges, vol. 20, no. 1, pp. 19-38, 2016.

[30] D. Player, "Take me home country roads?: Exploring the college attendance pattern of rural youth. Rural Opportunities Consortium of Idaho, 2015. [Online]. Available: http://www.rociidaho.org/take-me-home-country-roads-exploring-the-college-attendance-p atterns-of-rural-youth/

[31] J. L. Taylor, "Accelerating pathways to college: The (in)equitable effects of community college dual credit," Community College Review, vol. 43, no. 4, pp. 355-379, 2015, doi: $10.1177 / 0091552115594880$.

[32] K. L. Hughes, O. Rodriguez, L. Edwards, and C. Belfield, "Broadening the benefits of dual enrollment: Reaching underachieving and underrepresented students with career-focused programs," James Irvine Foundation, San Francisco, CA, 2012. Available:

http://ccrc.tc.columbia.edu/media/k2/attachments/broadening-benefits-dual-enrollment-rp. pdf

[33] R. A. Petrin, K. A. Schafft, and J. L. Meece, "Educational sorting and residential aspirations among rural high school students: What are the contributions of schools and educators to rural brain drain?," American Educational Research Journal, vol. 51, no. 2, pp. 294-326, 2014, doi:10.3102/0002831214527493.

[34] C. Carrico, H. M. Matusovich, and M. C. Paretti, "A qualitative analysis of career choice pathways of college-oriented rural central Appalachian high school students," Journal of Career Development, vol. 46, no. 2, pp. 94-111, 2019, doi: 10.1177/0894845317725603. 